\title{
Institutional support for professional competence of librarians to improve the codification and preservation of traditional knowledge in the libraries
}

\author{
${ }^{1}$ Lazarus, G. N., ${ }^{2}$ Jinadu, I., ${ }^{3}$ Eddy-Ugorji, D. C., and ${ }^{4}$ Imam, Abayomi \\ ${ }^{1} \&$ College Library, Adeniran Ogunsanya College of Education, Oto/Ijanikin, Lagos; \\ ${ }^{3}$ National Library of Nigeria; ${ }^{4}$ Michael Otedola Primary Education, Epe \\ E-mail: ${ }^{1}$ nnekalazarus@gmail.com; ${ }^{2}$ iliasujinadu@ gmail.com; \\ 3deceyugorji@yahoo.com; ${ }^{4}$ abayomimam16@yahoo.com
}

\begin{abstract}
Codification and preservation of traditional knowledge is of great importance, more so by professionals from the library and information science. Acquisition and management of traditional knowledge in academic libraries is one of the evolving areas of research and this is why this paper examined the impact of institutional support for professional competence of librarians to improve the codification and preservation of traditional knowledge in Lagos State, Nigeria. It provides a perspective from which institutional support can be viewed as an important element for codification and preservation of traditional knowledge in the libraries. In addition, the paper identified institutional support as funding, motivation, staff training/development, facilitative policy; including the inadequacies. The paper discussed the concept of professional competence and the competences required of professional librarian for codification and preservation of traditional knowledge in the library. This include: educational qualification, understanding the source of traditional knowledge, ability to locate traditional resources, possession of knowledge of traditional knowledge codification and preservation, Information and Communication Technology (ICT) skills. In conclusion, the paper reiterated that there is need to include other librarians apart from the library management staff in the formulation of institutional policy for improvements in codification and preservation of traditional knowledge in Lagos State. Moreover, the library management should make adequate provision for regular training and retraining of librarians to improve the codification and preservation of traditional knowledge in Lagos State.
\end{abstract}

Keyword: Codification, institutional support, preservation, professional competence, traditional knowledge.

\section{Introduction}

Library and information science as a discipline has evolved lately to raise questions on what the community of practice has done to facilitate the codification of traditional knowledge. In particular, institutional support has a decisive influence on the speed and efficiency of codification of traditional knowledge in the libraries (Chinomona \& Moloi, 2014). The activities and roles implemented by the institutions, whether on local, regional or national level, are necessary and important because they create an institutional support which generates and accelerates staff training and development. Institutional support for codification of traditional knowledge requires dedicated technology and funding as it affects all knowledge systems (Elnakla, D., McNally, B \& Elnakla, S, 2019). For this reason, Ishola (2014) recognized that traditional knowledge outputs and objectives are strongly facilitated by appropriate funding mechanisms. Since there is a need for a holistic co-ordination and collaboration of all stakeholders and resources in the traditional knowledge system, appropriate traditional knowledge funding streams are vital for curriculum development, public understanding, practice and accreditation, research and development, innovation as well as its codification and preservation (Jegajoth \& Sudha, 2015).

There are some indicators that, to a large extent, determine the effectiveness of institutional support for codification and preservation of traditional knowledge in the libraries. These indicators include library personnel, funding, motivation, facilitative policy and staff development. Institutional support is a general reflection of financial and technical support from the institution and its agency, which provides 
Lazarus, G.N., Jinadu, I., Eddy-Ugorji, D.C. and Imam, Abayomi: Institutional support for professional competence of librarians to improve the codification and preservation of traditional knowledge in the libraries

the libraries with critical resources that, may be used for codification of traditional knowledge for preservation in the libraries (Lazarus, Unegbu and Opeke, 2020). Support from the institution and library management allows librarians to interpret policies and programmes correctly in selection and acquisition of library resources (Peng, 2012). According to Lazarus, Unegbu and Opeke (2020), institutions set legitimate requirements for and provide external resources supporting the libraries in codification of traditional knowledge.

It is important to mention that institutional support provides critical external resources that foster codification, facilitative policies and regulations that protect the traditional community's intellectual property rights and rewards innovators by granting legitimacy (Liu, Han, \& Zhou, 2011). Some researchers such as Jegajoth and Sudha (2015) have found that every institution deals with its members through facilitative policies and decision making procedures. Hence, institutional support motivates librarians to acquire, codify and preserve traditional knowledge (Shu,Wang,Gao, \& Liu, 2015). Furthermore, it is observed that conventional knowledge documentation has avalanche of strategies and infrastructure but seemingly not so with traditional knowledge. Codification of traditional knowledge cannot be achieved without institutional support for professional competence of librarians in the libraries. The tendency among library and information professionals has been to emphasize on recorded knowledge (conventional knowledge) at the expense of unrecorded IK (Ngulube, 2002) but this may be as a result of insufficient institutional support in the libraries such as funding, motivation, facilitative policy and staff development for proper codification of traditional knowledge to be preserved in the library and information centers. This is particularly important for addressing the issue of codification and preservation of traditional knowledge in the libraries. This paper therefore focused on institutional support for professional competence of librarians to improve the codification and preservation of traditional knowledge in Lagos State, Nigeria.

\section{Concept of traditional knowledge}

Nnadozie (2013) described traditional knowledge as Indigenous Technical Knowledge, Indigenous Skill (IS) and People's Knowledge, Folk Knowledge, Rural People's Knowledge, EthnoScience, Oral Tradition and Cultural Science. In order words, it is the traditional knowledge of the local community existing within and developed around the specific conditions of women and men indigenous to a particular geographical area. In the opinion of Ngulube, Dube and Mhlongo (2015), traditional knowledge is a multifaceted, dynamic, and eclectic know-how that is spiritually, culturally, economically, socially and politically embedded in a unique local geographical context. To Mposhi, Manuyeruke and Hamauswa (2013), it is the body of knowledge held by people who are not regarded as developed as far as modern science and civilization is concerned.

Traditional knowledge, according to Mehta, Alter, Seneli and Maretzki (2016), is a local knowledge accumulated by communities over generations reflecting many years of experimentation and innovation in all aspects of life. Soh and Omar (2012) posited that it is a composition but holistic set of know-how, expertise, and skills derived from different sources. Makinde and Shorunke (2013) forwarded that traditional knowledge is a knowledge that an indigenous community accumulates over generations of living in a particular environment. This implies that the knowledge was generated, developed and used by certain people in a certain area and not limited to indigenous peoples. To Anaeto, Asiabaka, Nnadi, Aja, Ajaero, Ukpang and Ugwuoke (2013), it is a body 
Lazarus, G.N., Jinadu, I., Eddy-Ugorji, D.C. and Imam, Abayomi: Institutional support for professional competence of librarians to improve the codification and preservation of traditional knowledge in the libraries

of knowledge built up by a group of people through generations living in close contact with nature and such evolves in the local environment and adapted to the requirement and conditions of local people. Asiabaka (2009) in his own point of view sees indigenous knowledge as the knowledge used by local people to make a living in a particular environment, evolves in situations and constantly growing to meet new conditions. Emeagwali and Dei (2014) offered a comprehensive definition of traditional knowledge as the cumulative body of strategies, practices, techniques, tools, intellectual resources, explanations, beliefs and values accumulated over time in a particular locality, without the interference and impositions of external hegemonic forces. Traditional knowledge refers to the particular values, beliefs, rituals, traditions and environmental relationships that exist in a rural community.

Addressing the concept from a different perspective, Anaeto, et al (2013) describes traditional knowledge as a unique local knowledge existing within and developed around the special conditions of rural community of a particular geographical area. Traditional systems are localized African systems developed over long education and revitalization whose patterns are based upon local knowledge systems and expressed in local languages. Traditional knowledge is seen as that which is based on a combination of cultural distinctiveness and territorial occupancy or relative population that has its own distinctive culture. Traditional knowledge should then be taken to be localized knowledge that arise out of a certain locality and are unique to that locality. Asogwa (2013) asserted that before the European conquest of Africa, Africans had built a pool of knowledge and technology with which they sustained agriculture, human and animal health, timber seasoning, and fermentation of beverages, mulling of dyes, mining and architectural engineering. These are knowledge systems that are orally passed from one generation to the next and provides solutions to most problems faced by people as they interacted with their environment as well as living in harmony with nature. This implies that indigenous knowledge has to do with the people's cognitive and wise legacy as a result of their interaction with nature in a common territory.

Traditional knowledge as pointed by Adesiji, Komolafe and Ibrahim (2014) is a means of transmitting specific human elements from generation to generation. Traditional knowledge is central to Africa's development in all ramifications and manifest in all peoples and cultures across the world. As forwarded by Turner (2014) traditional knowledge are ideals we had that give significance and meaning to our lives and hence underpin our beliefs, influencing the decision we make, the actions we take and the life we lead. Nnadozie, Nnadozie, Ogugua, Egwim, \& Ossai-Onah (2015) in their explanation of traditional knowledge pointed out that every known community holds human life as sacred and that is why murder and suicide amongst its members are seen as anathema. Lehman (2014) that posited that traditional knowledge propagates through society as statements or propositions that are accepted by the recipients, often as the result of a communicative act. A proposition, according to Lacewing (2015), is what is claimed by an assertion or expressed by a complete declarative sentence. Ready examples of this was expressed by Nnadozie (2013) as pouring libation to appease the gods, making sacrifices before the commencement $f$ each farming season and creation of totems. Another description of traditional knowledge as narrated by Wiseoneking (2015) is on the issue of python in Igbo land especially in Idemili South Local Government Area of Anambra state where 
Lazarus, G.N., Jinadu, I., Eddy-Ugorji, D.C. and Imam, Abayomi: Institutional support for professional competence of librarians to improve the codification and preservation of traditional knowledge in the libraries

python is treated with utmost respect and dignity.

\section{Concept of professional competence}

The term profession was derived from a Latin word 'profiteo,' meaning to profess, which can also have the connotation of making a formal commitment in the sense of taking a monastic oath. This root might suggest that a professional is someone who claims to possess knowledge of something and has a commitment to a particular code or set of values, both of which are fairly well-accepted characteristics of professions (Mulder, 2017). Professionals deal in matters of vital importance to their clients and are therefore entrusted with grave responsibilities and obligations. Given these inherent obligations, professional work typically involves circumstances where carelessness, inadequate skill, or breach of ethics would be significantly damaging to the client and/or his fortunes. In addition, professionals hold themselves ultimately accountable for the quality of their work with the client. On the other hand, Lester (2014) observed a professional as a person who embodies the idea inherent in profiteer. Adubra, (2014) described professional as the standards of education and training that prepare members of the profession with the particular knowledge and skills necessary to perform the role of that profession.

Competency is a dynamic combination of a number of parameters which include knowledge and its use, skills, attitudes, descriptive results in learning outcomes of acquisition of training program and module. Epron (2015) stated that the notion of competency can include formal qualification, as well as such elements as an ability to transfer skills and knowledge in a new professional situation or ability for innovations. Competency level can be assessed based on a person's ability that is disclosure of personal characteristics of a specialist to use skills in possession.
Baumert and Kunter (2013) forwarded that competency is understood as acquisition and demonstration of knowledge, skills, behavior patterns and attitudes, required for a certain labor activity. Competency is a didactic unit of acquisition a combination form of knowledge, skills, attitudes that allows coping with set tasks (Baumert \& Kunter, 2013). In line with this, Dzerviniks (2016) noted that competences promote realization of a specialist in a certain field of professional activity. Competencies refer to inputs which help to achieve successful performance at work which is the ability to control and operate the things in the environment and the environment itself. Competencies required for a post are identified through job analysis or task analysis, using techniques such as the critical incident technique, work diaries, and work sampling (Robinson, 2010).

Over the years, librarians have successfully established practices and skills to handle the storage, retrieval and dissemination of information. While the traditional skills such as classification, cataloguing, indexing, user education are relevant even in the present age, the library professionals should acquire skills to deal with information in the new electronic environment. Competency is the capability of an individual to apply or use a set of related knowledge, skills and abilities required to successfully perform a given set of tasks in a defined work setting. A study was carried out by Okoye (2013) on assessment of competencies of professional librarians in Federal Universities in South East, Nigeria. The study investigated professional competencies that are currently expected of library professionals in academic libraries. The study centered on knowledge-based and skills'-based acquisition. Findings of the study showed positive correlation between acquired and applied knowledge from library school and place of work respectively but found no 
Lazarus, G.N., Jinadu, I., Eddy-Ugorji, D.C. and Imam, Abayomi: Institutional support for professional competence of librarians to improve the codification and preservation of traditional knowledge in the libraries

correlation between acquired and applied skills from library school and place of work respectively.

Boyatzis (2008) opined that professional competence is a set of related but different sets of behavior organized around an underlying construct, which is called "intent". The behaviors are alternate manifestations of the intent, as appropriate in various situations or times. Machaland and Horvat, (2008) carried out a study on competency-based lifelong learning of librarians in Croatia: an integrative approach. The purpose of the paper was to present the main findings of a nation-wide online survey of Croatian LIS stakeholders, library practitioners, mainly graduate librarians and library managers regarding subject-related competencies and further CPD activities in perspective of lifelong learning of librarians. Result shows that participation in formal and informal learning opportunities has proved to be intrinsically motivated, self-directed and driven by pragmatic reasons - a wish to improve working skills and increase self-confidence.

Mulder (2017) opined that professional competence is the generic integrated and internalized capability to deliver sustainable effective (worthy) performance (including problem solving realizing innovation, and creating transformation) in a certain task situation, professional domain, job, role and organizational and societal context. It can also be described as an articulate and complex combination of skills and capabilities that result from a conceptual and functional synthesis of theoretical aspects, linked to disciplinary contents and current experience. Professional competencies can be used to design and develop job postings, position descriptions, training and education programs and performance evaluation programs. According to Abotalebi and Biglu (2017) professional competence are directly associated to the performance, helpfulness of performance, and the importance of the accomplished work. Deildok (2016) opined that different types of libraries demand different types of professional competence, just as different library jobs require different types of library competence.

\section{Codification and preservation of traditional knowledge}

Kimble (2013) sees codification as converting tacit knowledge into explicit, usable form Converting undocumented information into documented information, representing and organizing knowledge before it is accessed and making institutional knowledge visible, accessible, and usable for decision making. Ruggles (2011) and Davenport and Prusak (2010) view codification as the primary vehicle by which knowledge becomes portable, reusable or transferable within the organization. Codification of knowledge into information is seen as the predominant mechanism by which knowledge transfer in organizations can be achieved. Davenport and Prusak (2010) and Ruggles (2011) place particular emphasis on knowledge codification as a way of affecting the transfer of knowledge. Codification can simply be taken as a process by which knowledge is made explicit, whether it be tacit knowledge or not. In line with this, Yunnus (2017) believe that codification is a valuable knowledge translated into an explicit form, often referred to as codification of knowledge in order to facilitate more widespread dissemination. Yunnus (2017) went further to describe codification as the creation of content categories. The fewer the number of categories, the more abstract the codification scheme. It is assumed that well-codified abstract content is much easier to understand and apply than highly contextual content.

Jabar, Sidi and Selamat (2010) carried out a study on tacit knowledge codification in Malasia. They stated that in managing and preserving knowledge and 
Lazarus, G.N., Jinadu, I., Eddy-Ugorji, D.C. and Imam, Abayomi: Institutional support for professional competence of librarians to improve the codification and preservation of traditional knowledge in the libraries

competencies as a strategic advantage to an organization. There are difficulties in documenting, capturing, storing, sharing and reusing all this knowledge. The study presented knowledge extract, profiling and sharing network framework to facilitate the codification and competencies management and adapting knowledge management processes in documentation, capturing, storing, sharing and reusing knowledge and competencies. The essence of codification is for people-to-documents approach, where knowledge is extracted from the person who developed it, made independent from that person, and reused for various purposes.

The idea that knowledge needs to be codified is central to many claims that knowledge can be managed. International Institute of Rural Reconstruction (IIRR) reported that traditional knowledge could be codified in form of descriptive texts such as reports, inventories, maps, matrices and decision trees. Other ways of codification include: audiovisuals such as photos, films, videos or audio cassettes as well as dramas, stories, songs, drawings, seasonal pattern charts, daily calendars and so on. It could also be stored in local communities, databases, card catalogues, books, journals and other written documents, audiovisuals and museums (Abioye, Zaid \& Egberongbe, 2011). Ngulube, Dube, and Mhlongo (2015) were of the opinion that traditional knowledge needs to be codified into print and electronic formats, both audio and video, to make it widely accessible through the global information infrastructure. Ebijuwa and Mabawonku (2015) in a study conducted in Oyo-State Nigeria examined the role of alternative health practitioners in primary healthcare delivery in Oyo State. It is aimed at determining the codification and use of traditional knowledge in primary healthcare by practitioners of alternative healthcare given the dearth of scholarly works in this area in library and information studies.
They found that health practitioners were codifying their traditional knowledge by writing them in a book, audio recording, videotaping, drawing, photographing and storytelling.

According to the research carried out by Matthew (2013) on knowledge management and the limits of knowledge codification, codification of knowledge into information is seen as the predominant mechanism by which knowledge transfer in organizations can be achieved. The study was carried out in Birmingham. The result shows that codification captures and represents knowledge be it explicit or tacit so that it can be re-used either by an individual or an organization. Matthew (2013) equally adds that abstracts and connotation can be provided for each document so as to make IK materials become easily accessible to all. Muswazi (2001) observed that some libraries have catalogued palm leaf manuscripts of the IK collection in their libraries noting that it is not sufficient enough as this merely shows the location and not the content of the manuscripts. Mabawonku (2002) recommends that at the national level, there should be depository laws guiding the deposit of projects and audiovisual recordings to local or state branches of the National Library of Nigeria.

\section{Professional competence for codification and preservation of traditional knowlege}

David, Johnson, Ehrlinger and Kruger (2013) emphasized that competences are gained as a result of an acquisition of the disciplines cycle content of subject's training, undergoing professional practice and fulfillment of the course and graduate qualification works by the staff. Competences promote the acquisition of professional activity and further professional improvement. In the content of codification and preservation of traditional knowledge, the librarians' 
Lazarus, G.N., Jinadu, I., Eddy-Ugorji, D.C. and Imam, Abayomi: Institutional support for professional competence of librarians to improve the codification and preservation of traditional knowledge in the libraries

competence should include: educational qualification, understanding the source of traditional knowledge, ability to locate traditional resources, possession of knowledge of traditional knowledge codification and preservation, Information and Communication Technology (ICT) skills.

\section{Professional competence and educational qualification}

The word education is derived from the Latin word 'educare' meaning to raise and to bring up. According to National Council of Educational Research and Training (NCERT, 2014) the word education has originated from another Latin term 'Educere' which means to lead forth or to come out. The term education has been interpreted by different people in different ways. Some people refer to it as formal schooling or to lifelong learning. Some others refer to it as acquisition of knowledge, skills and attitudes. Some say that education is nothing, but training of people's mind in a particular direction to bring about desired changes. According to Sarkisov (2018) education can be defined by the type of educational institution which would depend on the type of profession, duration of training and the degrees obtained. To Thapan (2006) education is nothing but a purposeful activity, deliberately planned for the optimum development of an individual's potentials and competency. It is considered to be a life- long process, where all the experiences, knowledge and wisdom that an individual acquires at different stages of one's life through different channels that is either formally nor informally. In the opinion of (NCERT, 2014) education is considered as an act or experience that has formative or additive effect on the personality of an individual.

Over the years, library professionals have constructed their own ways of looking at and relating to the world and to each other. Educational qualification or aspects of education such as literacy, knowledge, and mental development are among the domains of human life considered in the construction of determinants of professional competence in most of the institution, organization and governmental social monitoring frameworks. From an organizational point of view, according to (Bol \& Van de Werfhorst, (2011) educational qualification encompasses legal compliance and managing risk, acknowledging the value of employees, motivating competence breeds competence, providing for succession planning and building organizational skills and knowledge. Brauer and Dymitrow (2014) opined that an educational qualification proves that the holder has passed certain exams and is thus in possession of corresponding competencies and knowledge.

\section{Understanding the sources of traditional knowledge}

In identification of sources of traditional knowledge, it is embedded in community practices institutions, relationships and rituals (Adesuji et al, 2014). According to Nakashima, Prott and Bridgewater (2000), it is an essential tacit knowledge that is learned through repetition, not easily codifiable, transmitted orally and experimental rather than theoretical knowledge. Grey (2014) pointed out that traditional knowledge may be gained through trial and error (experimentation), ritual, institution or inspiration, observation, dreams or visions, and interaction with non-human entities and through apprenticeship and peer-to-peer exchanges with other knowledge holders.

Ukwuoma (2015) stated that traditional knowledge is derived from knowledge that is passed down from generation to generation through words of mouth and rituals. Studies of rural communities by experts in different parts of the world have shown that traditional knowledge evolves through unintended 
Lazarus, G.N., Jinadu, I., Eddy-Ugorji, D.C. and Imam, Abayomi: Institutional support for professional competence of librarians to improve the codification and preservation of traditional knowledge in the libraries

experimentation, fortuitous mistakes and natural selection by farmers, as well as the practical judgment and skills needed to survive in a fragile soil system and environmental challenges. Nnadozie, et al (2015) asserted that a good number of human settlements have gained beneficial knowledge from careful observation of the hostile and challenging environments in which they live. This assertion showed that the rural populace most especially the farmers, is the custodian of indigenous knowledge systems. Soh and Omar (2012) opined that indigenous knowledge skills are derived from different sources such as the parents, indigenous experts (elders), empirical trails and even scientific information. In addition to this, village elders, bards, folklorists, native historians, chief priests and traditional rulers are the main custodians of the history, tradition and culture of each community or society.

In tracing the sources of traditional knowledge, mention must be made of elders of the community generally. Elders observe experiment and a unique knowledge in the course of their lifetime. They are a repertoire of experiences and wisdom in different areas of human behavior. Knowledge of morals, local midwifery techniques and culinary skills reside in some wizened old women in rural communities. For instance, an example cited by World Bank (2004) on indigenous postpartum, maternal and child health care rites in Igbo people, south-eastern Nigeria stated that during a four-week period after birth called "Omugwo", the mother and the child are secluded and relieved of all other chores. They are cared for by the grandmother of the new born. The new mother is given a stimulating hot soup made with dried fish, meat, yam, plenty of pepper and a special herbal seasoning called "Udah" which makes the uterus contracts and thus helps in expelling blood clots. The diet helps to restore blood lost during childbirth, restores energy, facilitates the healing of wounds, restores normal bodily functions and promotes lactation. For a first time mother, the time is spent learning parental and housekeeping practices from her mother.

\section{Possession of knowledge of traditional knowledge codification and preservation} Husain and Nazim (2013) referred to knowledge as an intangible asset which has taken precedence over traditional organizational resources such as capital and labor. Kim and Abbas (2010) defined experience as justified personal belief that increases an individual's capability to take effective action. Kebede (2010) explained knowledge of both explicit to be expressed in words or number and can be documented or stored in databases as electronic records. Examples include a telephone directory, an instruction manual or a report of research findings. They went further to explain tacit knowledge as a subjective and experience based knowledge difficult to articulate or write down. Tacit or implicit knowledge is that knowledge that resides in the brain. It is highly personalized and difficult to communicate and share. It can be shared between people through discussion, stories and personal interactions. It includes skills, experiences, insight, intuition and judgment. Meanwhile, Nnadozie, Emerole, Igwe and Nnadozie (2015) states that explicit knowledge resides in an organization in terms of reports, documents manuals procedures. It can easily be communicated, shared, transferred and disseminated. It is pertinent to note that knowledge is implored to utilize and exploit organization through the application of employee's skills, experiences, ideas, intuitions, commitments, motivations and imaginations in order to create new line of products and services.

Uzohue and Yaya (2016) posits that in Nigerian libraries, with the exponential growth of human knowledge in a variety of format, they must analyze 
Lazarus, G.N., Jinadu, I., Eddy-Ugorji, D.C. and Imam, Abayomi: Institutional support for professional competence of librarians to improve the codification and preservation of traditional knowledge in the libraries

the needs of their users, locate and form useful websites and knowledge sources from the internet for their clienteles. Libraries should develop means to capture all the tacit knowledge that is embedded in people's skills and competencies as well as the explicit knowledge found in the working processes of information professionals in the libraries.

\section{Knowledge of Information Communication Technology (ICT) skills} Documentation of IK needs to be a conscious endeavor especially in view of the professional competence in the library already discussed. Appropriate education and training are essential components of the process. To this end, professional librarians need to work together to formulate strategies to equip librarians with appropriate competencies and skills (Harris, 2014). According to Adam (2008), not only are Information Communication Technology (ICT) important in carrying out the core functions of libraries, they are also important tools in indigenous knowledge activities. It is thus reasonable to expect that librarians should be conversant with ICT in order to provide effective services in the library. Handoko, Nursanti, Harmanto and Sutriono (2016) opined that knowledge is a significant part of technology itself. Developing communities have considered knowledge to be a main factor in the implementation of new technologies. According to Akinwale (2012) the emergence of new technologies for rapid dissemination of knowledge is known as digital revolution, accompanying the development of science and technology since the wake of the Second World War. The study carried out by Akinwale (2012) examines digitization of indigenous knowledge as a critical resource for the promotion of effective management of natural resources in Africa. The findings reveal several opportunities and challenges in attempts to promote African approaches to natural resources management since the advent of the digital revolution. Africans' experience of digital revolution is discussed with reference to success stories of digitization of indigenous knowledge systems.

Greyling and Zulu (2010) suggested that libraries need to document other knowledge and use information technology not only to render the knowledge accessible but also to preserve it. Information and communication technologies (ICTs) play a critical role in the documentation and preservation of indigenous knowledge (Chisa \& Hoskins, 2014). Taking a critical look at the scientification of IK by creating databases for purposes of documentation, and accessibility, Nakata and Langton (2005) identifies three aspects, namely, particularization, validation and generalizations. In their explanation, particularization is the process of identifying useful aspects of traditional knowledge, which are then validated to determine their truthfulness. They said that once this is established, the identified aspects are documented and made available to others while generalization is the final component of the process.

Owiny, khanjan and Maretzk (2014) carried out a research on the use of social media technologies to create, document, preserve, and disseminate traditional Knowledge and Skills to Communities in East Africa. The result shows that high rate of illiteracy (printbased) in rural Africa and the exclusion of traditional knowledge from Western education add to the information gap experienced in rural Africa. It was discovered that challenges facing oral cultures are the disappearance of traditional knowledge and skills due to memory loss or death of elders and the deliberate or inadvertent destruction of traditional knowledge. Furthermore, Wendland (2008) noted that libraries are also repositories of formal scientific and indigenous and other cultural materials 
Lazarus, G.N., Jinadu, I., Eddy-Ugorji, D.C. and Imam, Abayomi: Institutional support for professional competence of librarians to improve the codification and preservation of traditional knowledge in the libraries

that provide vital preservation, educational, scholarly and functions for the benefit of whole society. A sediment echoed by Greyling (2010) in that for libraries to meet their social obligations they have to provide access to information from the oral, digital and any other media in which it is supplied. Since ancient time, vital information on health, child rearing, natural resources management is often encoded in unique forms such as proverbs, myths, rituals, and ceremonies. With the advent of technology, it is imperative to look for ways of processing indigenous knowledge in the same way as scientific information. ICT plays major roles in improving the availability of indigenous knowledge systems and enhancing its blending with the modern scientific and technical knowledge. According to Adam (2008) ICT can be used to:

i. capture, store and disseminate traditional knowledge so that it can be preserved for the future generation,

ii. promote dissemination of traditional knowledge,

iii. create easily accessible traditional knowledge information systems,

iv. promote integration of traditional knowledge into formal and nonformal training and education, and

v. provide a platform for advocating for improved benefit from traditional knowledge systems of the poor.

In other words, proper application of ICT is essential to stimulate the flow of indigenous knowledge and the incorporation of modern scientific and technological understandings to traditional knowledge. Scientific weather forecasts may be more credible to a local community, if ways are found to integrate them with traditional knowledge that local people have relied on for generations.

\section{Institutional support for codification and preservation of traditional knowledge}

Institution is often used interchangeably with the term Organization both in speech and in literature. However, there are other synonyms abound. According to Uphoff and Buck (2006), institution constitutes norms and behaviors that persist over a long period in time by serving socially valued purposes. Institutions have also been identified to exist to shape human interaction by establishing a stable structure through which the set down rules (formal) and norms (informal) that characterize human behavior in a given situation (Chinomona \& Moloi, 2014). Institutions exist to define human behavior by prescribing a set of constraints (norms of behavior, conventions and rules) and incentives which affect individual choices which in the long run affects the output of economies and societies. Institution is referred to deep aspects of social structure, which act as authoritative guidelines and constraints for behavior (Scott, 2005). Institutions are taken-for-granted rules that can be explicit and consciously perceived by individuals, or can be as implicit guidelines for individual's actions (Ute, Uhlaner and Stride, 2015).

In a 2005 study conducted by Gorjestani (2005), it was established that multilateral development organizations, local and global NGOs, policy makers, education institutions and the private sector, such as library and information centers, are among some institutions that have shown interest in traditional knowledge. In the field of development, for example, there is an interest to identify and apply culturally appropriate knowledge to development practices. For some countries in Africa such efforts are leading to more culturally sensitive development plans (Dei, 2000) to better serve individual country's needs. In addition, the revitalization and restoration of this knowledge can make it globally 
Lazarus, G.N., Jinadu, I., Eddy-Ugorji, D.C. and Imam, Abayomi: Institutional support for professional competence of librarians to improve the codification and preservation of traditional knowledge in the libraries

available for policy makers or practitioners to access and inform global policies and programs.

Agarwal (2002) specifically questions whether traditional knowledge is appropriately captured and represented in these institutions. He mainly attacks databases, where most forms of traditional knowledge are stored at an international level, and argues that knowledge is organized into data bases and institutionalized solely based on the biases of the development practitioner or database manager. There are increasing demands and recognition of traditional knowledge and its importance in library and information centers but little efforts are still being made to document the knowledge in the libraries. Some studies have been done on codification of traditional knowledge in Nigeria, among the recent studies is Ebijuwa and Mabawonku (2015), none of these studies have really investigated the role of institutional support in codification and preservation of traditional knowledge in libraries. Morrow (2011) posits that institutional support in codification and preservation of traditional knowledge in the library is based on funding, Library personnel, motivation, staff development and training, facilitative policy.

\section{Funding}

The major fund provider for library administration and development is the parent institution. According to Ishola (2014), for effective services and survival, library budget should consider profit potentials and be related to operational costs and service expectation. In Ishola's explanation, traditionally, a fixed percentage of the parent institution's recurrent budget is set aside for library services. The primary purpose of the libraries is to support teaching, learning, and research in ways consistent with, and supportive of the institution's mission and goals. Library resources and services should be sufficient in quality, depth, diversity, and currency to support the institution's curriculum. As a result of this, libraries are often considered the most important resource center of institutions. However, Ahmed and Nwalo (2013) recognized that adequacy of fund helps in the provision of qualitative and quantitative information materials, staff and other facilities to enhance the sustainability of departmental/ faculty libraries in Nigerian Universities.

To Ahmed and Nwalo (2013), it is quite unfortunate that the academic libraries hardly receive adequate fund. Meanwhile, according to Ishola (2014) funding is an area that is open for more discussion in the libraries in terms of funding and separate funding support system from both state and federal governments. Ishola (2014) confesses that though LIS enjoy the support of the Federal Ministry of Education and Information as well as National University Commission (NUC) and Library Registration Council of Nigeria (LRCN) as regulatory bodies, this support is not well defined and anchored statutorily by any enabling instrument such as decree, law, statutes or any government legislative instrument.

Albert (2006) asserted that libraries are the cornerstone of civil societies and liberal democracies which have come to be cherished by all and must not be allowed to crumble into disuse. Albert (2006) further stressed that book collection in an academic library should have both depth and breadth because it needs to address a wide range of subjects, and it needs a sufficient number to give those subjects the coverage it deserves. Albert however, wondered why libraries are poorly funded. University libraries provide an absolutely fundamental service which affects the whole of the university and without which it would cease to function as a center for teaching and research. Hence, the library is the university's central organ and must be properly supported financially. This means 
Lazarus, G.N., Jinadu, I., Eddy-Ugorji, D.C. and Imam, Abayomi: Institutional support for professional competence of librarians to improve the codification and preservation of traditional knowledge in the libraries

that adequate funding should be considered a basic necessity for the effective development of libraries.

\section{Motivation}

Nwibere (2014) opined that motivation is a human psychological characteristic that contributes to a person's degree of commitment to work. It includes the factors that cause, channel, and sustain human behavior in a particular committed direction. There are basically two types of motivation, extrinsic and intrinsic motivation. Extrinsic motivation: this motivation is induced by external factors which are primarily financial in nature. These incentives and reward have been subjects of debate, whether they really motivate the employees or simply move them to work. Consequently, their motivation is crucial in determining the level of their commitment to work.

\section{Staff training/development}

The benefits of institutional support in a library can manifest through the effectiveness of training, improve recruitment, identification of training gaps which lead to improved efficiency, productivity, worker safely and employee retention. According to Trinder (2008), institutional support is typically based on a prescribed level of training. Training is designed to help people achieve the required outcomes, whatever the particular task the individual is requested to undertake. Such training is intended to avoid theoretical training and concentrate on skills formation; so that once the training is completed the graduates have the necessary skills to do the work required of them. The training must therefore be based on a set of competency standards.

Kubuga (2014) carried out a research on assessing the impact of Institutional support on training and development: a case study of the University for Development Studies (UDS). The research investigated the level of institutional support and how it has impacted on training and development behaviors and on commitment of staff and employees of UDS. Result revealed that a preference of teaching staff was over than non-teaching staff in relation to the enjoyment of available forms of institutional support. The study recommends that division needs to be strengthened through capacity building, while also putting in place firm policies in relation to the organizational support offered to employees. Materials and Resources must be made available to employees to enable them carry out their functions effectively, and efficiently in order to reduce material waste.

Oguche, Lamidi and Gabasa (2017) distinguishes between education and training arguing that education is broader in focus giving scope for wider application while training is more focused on a specific work environment. Training ensures that professionals remain relevant as it provides opportunities for new learning outside of the formal academic sector. Sturges (2015) posited that extensive focus is given to education at the expense of professional training. The value of professional development is discussed in various papers (for example, Raseroka (2003; Sturges (2015). Sturges (2015) also pointed out that it is through training that a professional is able to remain relevant and in a position to deal with changing environments. According to the Canadian Society for Training and Development (CSTD, 2011) training refers to a planned process to build skills and knowledge through specific learning experiences. Training is designed to ensure performance outcomes on tasks people do on the job. Performance refers to behaviors that produce measurable results and that indicate progress towards or achievement of an important outcome. Performance at the individual level depends on clear expectations, meaningful feedback, and having the resources, skills and 
Lazarus, G.N., Jinadu, I., Eddy-Ugorji, D.C. and Imam, Abayomi: Institutional support for professional competence of librarians to improve the codification and preservation of traditional knowledge in the libraries

knowledge, plus motivation to perform (CSTD, 2010).

Ugwu and Ezema (2010) recommend the minimum skills required for LIS professionals such as Library and information-handling skills; service orientation; ICT knowledge skills; communication and training skills; marketing and presentation skills; understanding of cultural diversity; and knowledge mapping skills. A staff component consistently exposed to relevant training and development interventions should not be underestimated. As stated by Connor (2009), an academic library's single most valuable resource is its workforce. Without educated, well trained, and motivated librarians and library staff, an academic library program is ill prepared to meet the needs of its clientele or the challenges that face institutions of higher education. Sturges (2015) opined that professional development includes the systematic maintenance, improvement and broadening of knowledge and skills. To Sturges (2015), it is the ongoing process that is aimed at monitoring and upgrading the skills of individual workers within the profession.

Raseroka (2003) asserted that one of the roles of libraries was to act as institutions where traditional knowledge content can be organized, documented, preserved, safeguarded and made accessible, recognizing the intellectual property rights in the various regimes. This view seems to highlight the need for both students and practitioners to manage, monitor and reflect on their professional development in order to ensure that they are well skilled and equipped to deal with developing needs and contexts of their customers. While affirming the place of academic qualifications, Sturges (2015) also pointed out that a profession is able to remain relevant and in a position to deal with changing environments. Davis and Lundstrom (2011) opined that libraries face a host of new challenges in terms of ways to stay relevant in the Information Age. Libraries are required to do more with less and the skills library professionals need continue to evolve. Responsibility for training should be handled by a section of the institution like the personnel, human resources or staff development units; or be considered as a separate unit of its own (Brandt, 2002).

Ilesanmi (2013) noted that the method of training should be diversified and made appropriate to the training needs of individual libraries. Some of the identified methods/techniques include conferences, continuing education courses, on the job training, seminars and workshops, vestibule training, case studies, case histories, self- study, electronic teaching media, simulation games and role playing. Others include internship, apprenticeship, modeling, study visits to developed libraries, and industrial attachment (Rosenberg, 2005). To Adeniji, Babalola and Adeniji (2012) library building and large collections without skilled professionals can be described as glorified warehouses. Nassazi (2013) agrees that training is the only way of developing organizational skill through building employees' competencies to succeed.

\section{Facilitative policy}

Collections are developed by librarians and library staff by purchasing or otherwise acquiring materials over a period based on assessment of the information needs of the library users. Library development includes creation of policies to guide material selection; replacement of worn or lost materials; weeding of materials that is no longer needed in the collection and planning for new collections. According to Ilesanmi (2013) libraries can help in collecting, preserving, and disseminating of traditional knowledge; publicizing the value, contribution, and importance of IK to both non-indigenous and indigenous 
Lazarus, G.N., Jinadu, I., Eddy-Ugorji, D.C. and Imam, Abayomi: Institutional support for professional competence of librarians to improve the codification and preservation of traditional knowledge in the libraries

people; involving the elders and communities in the production of IK and encouraging the recognition of intellectual property laws to ensure the proper protection and use of IK.

Leonard (2001) opined that libraries purchases and maintains collections that are sensitive to and accurately reflect native cultures. A culturally-responsive library seeks out sources of materials that may be outside the mainstream publishing and reviewing journals. This entails seeking local community input and suggestions for purchase. In addition, he suggested that library should encourage the development and preservation of materials that document and transmit local cultural knowledge, makes appropriate use of diverse formats and technologies to gather and make available traditional knowledge. Libraries develop policies for appropriate handling of culturally sensitive materials to ensure that existing materials are relevant and appropriate. This is in line with Sarkhel (2016) who opined that the collection development should focus on promotion of respect for cultural identity, traditions and religions and dialogue among cultures as a factor in sustainable development. Libraries therefore, feature prominently in this plan, most notably their role in providing access to content and traditional knowledge. By implication the role of libraries is extended to promote cultural heritage, support local content development and to enhance the capacity of indigenous peoples to develop content in their own language. Sarkhel (2016) suggested that before any collection of traditional knowledge can take place, the following should be done:

i. Define goals and objectives

ii. Set out a general area of operation where information is to be collected and community projects implemented

iii. Formulate questions for use during the study (It should be clear on how the data are to be collected and analyzed: qualitatively, quantitatively, or both);

iv. Establish who to talk to (i.e., the most resourceful individuals in the community), where such people are to be found, and how and when to meet them;

v. Develop the right relations with all key players in the project (such as administrators, traditional leaders, opinion leaders) by informing and sensitizing them;

vi. Formulate a plan of action, mobilize the necessary resources and put the required personnel and equipment in place.

Interviews, field works and observations are the best methods of collecting traditional knowledge while folklore, songs, poetry, and theater can reveal a great deal about a people's values, history, and practices. These are often not written down and need to be recorded.

Secondary sources include published and unpublished documents, videos, photos, museums, and exhibits. According to Nwibere (2014) in a library services context, awareness of the history, culture and values of major groups in a community and an understanding of cultural pluralism would constitute knowledge, which library staff would bring to bear on collection acquisition, service and program design.

Ondari-Okemwa (2014) opined that acquiring this knowledge is an active undertaking, requiring library staff to interact with community members and activities in addition to using formal sources of information such as census data or community profiles. Understanding forms through such cross-cultural interactions and immersion experiences.

Staff learns, for example, how knowledge is managed and imparted in the specific cultures within a community, and insight is gained into how members of a 
Lazarus, G.N., Jinadu, I., Eddy-Ugorji, D.C. and Imam, Abayomi: Institutional support for professional competence of librarians to improve the codification and preservation of traditional knowledge in the libraries

particular group are constrained or encouraged to gain information in an environment different from their cultural norm. Attitude drives awareness of personal prejudices and biases and attempt to mitigate or change them. In the opinion of Adedibu (2006) a well written facilitating policy should not be narrowing minded, it should be broad to cater for all aspects of development in the library. This is because policy is a vital instrument in making selections to support the curricula of any institution. Adedibu (2006) added further that it is necessary for the library to know its community and assess the needs of all segments of the community before formulating policy for the library.

\section{Conclusion}

The spate of literature on institutional support has proved that this is an important phenomenon in organizational productivity because it leads to positive results in the workplace. Institutional support is like the root of a tree that supports the whole tree and therefore caters for all the employees in the organization in terms of resources and personal needs. Institutional support leads to institutional effectiveness. This is a process in which organization officials demonstrate how well they succeed in accomplishing the institution's mission and meet the goals. The institutional support allows officials to choose expected outcomes based on a self-identified mission. The process of Institutional support involves planning, assessment, and using the assessment results for continuous improvement (Baranik, Rolling \& Eby, 2010).

The immense codifying and preserving of traditional knowledge was framed in Tella (2007) which stated that traditional knowledge encompasses all human interaction that can be captured, shared and used for developmental purposes. Traditional knowledge is unique to a given culture, community or society. It is contrasted and differentiated from the knowledge gained at formal institutions. A traditional knowledge system encompasses all aspects of life, such as the management of natural environment. Codification is one of the means of preserving traditional knowledge for posterity, national growth and sustainable development. Access to relevant information has been codified as crucial to the economic, political, and social wellbeing of any community. In traditional societies, there was hardly any effort at comprehensive codification of traditional medicinal knowledge. In rare cases where bare codification exists, it was usually in the traditional dialect of the local communities. On the influence of institutional support on codification and preservation of traditional knowledge, there is need for codification into print and electronic formats for both audio and video to make it widely accessible through the global information infrastructure.

In addition, it must be emphasized that the importance of institutional support on codifying traditional knowledge is to ensure that documentation and communication in libraries include some crucial factors such as paucity of professional and institutional documentarists; the tacit nature of traditional knowledge; the individualistic nature of indigenous knowledge and networking technology. It should be noted that traditional knowledge is mainly preserved in the memories of elders whose knowledge disappear when they die thus loosing traditional knowledge at a high rate. Codification of tradition knowledge is therefore essential for development and information purposes. Institutional support influences codification and preservation of traditional knowledge through certain activities such as funding the libraries in organizing seminars, workshops, debates, lectures, and exhibitions to advance the need to codify and preserve traditional knowledge. In other words, traditional 
Lazarus, G.N., Jinadu, I., Eddy-Ugorji, D.C. and Imam, Abayomi: Institutional support for professional competence of librarians to improve the codification and preservation of traditional knowledge in the libraries

knowledge does not flow on its own accord rather it needs owners or originators with the vision and motivation to create, adapt or exchange it.

\section{Recommendation}

1. There is need to include other librarians apart from the library management in the formulation of institutional policy for improvement in codification and preservation of traditional knowledge in Lagos State;

2. Library management should make adequate provision for regular training and retraining of librarians to improve competence in the codification and preservation of traditional knowledge in Lagos State;

3. There is need for the parent institution and library management to provide adequate fund to support the professional librarians in codification of traditional knowledge;

4. The Lagos State Ministry of Education in collaboration with the institutions and library management should incorporate traditional knowledge codification into the library education curriculum in order to promote the usefulness and its influence in libraries in Lagos State.

\section{References}

Abioye, A., Zaid, Y., and Egberongbe, $\mathrm{H}$. S. (2011). Documenting and disseminating agricultural indige nous knowledge for sustainable food security: The efforts of agricultural research libraries in Nigeria. Meeting of 78 information systems for indigenous knowledge in agriculture. Accessed online at http://conference.ifla.org/pastwlic/2011/78-abioye-en.pdf on $18^{\text {th }}$ December, 2020
Abotalebi, P., and Biglu, M. H. (2017). Identification of Competencies for Professional Staff of Academic Medical Libraries in Iran.Open Access Library Journal. Accessed online at https://www.researchgate . net/publication/317358422 on 18th December, 2020

Adedeji, O. A., Olafiaji, E. M., Omole, F. K., Olanibi, J. A., and Yusuff, L. (2014). An assessment of the impact of road transport on rural development: A case study of Obokun Local Government Area of Osun state, Nigeria. British Journal of Environmental Sciences, 2(1), 3448.

Adedibu, L. O. (2006). Collection development policy: the case of University of Ilorin library. Journal of Nigeria Library Association. 39(2) 11-14.

Adeniyi, M. A., Babalola, G. A., and Adeniji, S. E. (2012). Workers training programs in two Universities in libraries Nigeria. Library Philosophy and Practice (ejournal) Accessed online at: unlib.unl.edu/Lpp/ on $22^{\text {nd }}$ December, 2020.

Adesuji, G. B., Komolafe, S. E., and Ibrahim, M. (2014). Sources of indigenous knowledge on healing practices among farmers in Kwara State, Nigeria. Sarheed Journal of Agriculture, 30(2), 271-275.

Adeyemo, A. A., and Adebayo, J. O. (2017). Documentation and dissemination of indigenous knowledge by library personnel in selected research institutes in Nigeria.Library philosophy and practice (e-journal).Accessed online at https:// digital commons .unl.edu/libphilprac/1628 on the 10th December, 2020.

Adubra, E. (2014). Fragmentation of teacher Education: Responses from the teacher Task Force 
Lazarus, G.N., Jinadu, I., Eddy-Ugorji, D.C. and Imam, Abayomi: Institutional support for professional competence of librarians to improve the codification and preservation of traditional knowledge in the libraries

Network. Teacher Education Policy in Europe Network, 124. Zagreb: UNESCO.Accessed online at https://www .idi.hr /tepe 2014/eadubra.pdf on 15th August, 2020.

Agrawal, A. (2002). Indigenous knowledge and the politics of classification. International Social Science Journal 54(173):287-297.

Ahmed, A. O., and Nwalo, K. I. N. (2013). Fund allocation as a correlate of sustainability of departmental libraries in Nigerian Universities, Library Philosophy and Practice (e-journal). 936951.

Akinwale, A. A. (2012). Digitization of indigenous knowledge for natural resources management in Africa. Paper presented at the 20th Anniversary Summit of the African Educational Research Network at North Carolina State University, Raleigh, USA. Accessed online at: www.akeemakinwale.com.ng on Nov $3^{\text {rd }}, 2020$.

Albert, B. (2006). Alkek library, Texas State University, collection development policy.Accessed online at http://www.library. txstate.edu/about/departments/ac q/colldev/cdpolicy/cdpolicymain.html.

Anaeto, F. C., Asiabaka, C. C., Nnadi, F. N., Aja, O. O., Ajaero, J. O., Ukpongson, M. A., and Ugwoke, F. O. (2013). Integrating indigenous know ledge system in extension education. The potential for sustainable agricultural development in Nigeria. Research Journal of Agriculture and Environmental Management, 2(11), 332- 340.

Asiabaka, C. C. (2009). Agricultural extension: A handbook for development practitioners.

Omokun: Modsy farm united services,

Baranik, L. E., Roling, E. A.,and Eby, L.T. (2010). Why does Mentoring Work? The Role of perceived organizational support.Journal of Vocational Behaviour, 76, 366-373.

Baumert, J., and Kunter, M. (2013).The COACTIV Model of Teachers' Professional competence.Springer.Accessed online at http://www. Sprin ger.com/978-1-4614-5148-8 on 22nd September, 2020.

Bol, T., and Van de Werfhorst, H. G. (2011). Signals and closure by degrees: The education effect across 15 European countries. Research in Social Stratification and Mobility 29(1), 119132.

Boyatzis, R. E. (2008). Competencies in the 21 st century. Journal of ManagementDevelopment.27(1), 5-12.

Brandth, D. S. (2002).Writing a library training policy.Computers Libraries.22(6).Accessed online www.infotoday.com $>$ junoz $>$ bra ndt on $20^{\text {th }}$ November, 2020.

Brauer, R., and Dymitrow, M. (2014). Quality of life in rural areas: A topic for the rural development policy? Nicolaus: Copernicus University Press.

Canadian Association of Research Libraries (CARL, 2010). Accessed online at http:// www. carl-abrc.ca on $22^{\text {nd }}$ November, 2020

Canadian Society for Training and Development (CSTD, 2011). Competencies for training and development professionals. Accessed online at performanceandlearning.ca>ipl> $2015 / 10$ on $28^{\text {th }}$ November, 2020. 
Lazarus, G.N., Jinadu, I., Eddy-Ugorji, D.C. and Imam, Abayomi: Institutional support for professional competence of librarians to improve the codification and preservation of traditional knowledge in the libraries

Chinomena, E., and Moloi, K. C. (2014). The role played by institutional support in the commitment, job satisfaction and employee performance of teachers in Gauteng province of South Africa: A social exchange perspective. Mediterranean Journal of Social Sciences. 5(2), 20392117.

Chisa, K., and Hoskins, R. (2015). Decolonizing indigenous intellectual and cultural rights in heritage institutions: a survey of policy and protocol in South Africa. Mousaion. 33(3):55-72.

Davenport, T. H., and Prusak, L. (2010). Working knowledge: How organizations manage what they know. Boston, Mass: Harvard Business School Press.

David, D., Johnson, K., Ehrlinger, J. and Kruger, J. (2013). Why people fail to recognize their own incompetence. Current Directions in Psychological Science, 12(3) 83-7.doi:10. 1111/1467-8721.01235

Davis. E., and Lundstrom. K. (2011). Creating effective staff development committees: A case study. Library World, 112(7/8), 334-346.

Dei, G. S. (2000). Rethinking the role of IKS in the academy. International Journal of Inclusive Education, 4(2): 111-132.

Deildok, M. (2016). Future library competencies. Scandivian Library Quaterly. Accessed online at slq.nu>2016/09>slq3.20161.pdf on $12^{\text {th }}$ November, 2020.

Dzerviniks, J. (2016). Teacher training in the context of inclusive education: methodological dimension, society integration education. Proceedings of the International Scientific Conference, 1(79). Rezekne: RTA. Accessed online at: http://conference.ru.lv/ on $5^{\text {th }}$ November, 2020.

Ebijuwa, A. S., and Mabawonku, I. (2015). Documentation and Use of Indigenous knowledge by Practitioners of Alternative Healthcare in Oyo State, Nigeria. Afr. J. Lib. Arch. and Inf.Sc.25(1), 59-68.

Elnakla, D., McNally, B and Elnakla, S. (2019). The importance of institutional support in maintaining academic rigor in e-learning assessment. Doi: $\quad$ 10.1109/ICTCS.20198 923111

Emeagwali, G., and Dei, G.J.S. (2014). Anti-colonial educational perspectives for transforma tive change: African indige nous knowledge and the disciplines. Rotterdam: Sense publishers.

Epron, A. (2015). European adult education (young) professionals learning platform.Accessed online at http://www.aepro.eu/ 49.On $5^{\text {th }}$ October, 2020.

Gorjestani, N. (2005). Capacity enhancement through knowledge transfer: Capacity enhancement through knowledge transfer: A behavioral framework for reflection action and results. The World Bank: Washington D.C

Grey, S. (2014). Indigenous knowledge. Accessed online at http://works.bepress.com /samgrey/3/ on $5^{\text {th }}$ December, 2020. 
Lazarus, G.N., Jinadu, I., Eddy-Ugorji, D.C. and Imam, Abayomi: Institutional support for professional competence of librarians to improve the codification and preservation of traditional knowledge in the libraries

Greyling, E., and Zulu, S. (2010). Content development in an indigenous digital library: A case study in community participation. International Federation of Library Associations and Institutions (IFLA) Journal, 36 (1): 30-39.

Handoko1, F., Nursanti1, E., Harmanto, D. and Sutriono, B. (2016). The role of tacit and codified knowledge within technology transfer program on technology adaptation. ARPN Journal of Engineering and Applied Sciences, 11 (8), 564572.

Harris, D. N., and Sass, T. R. (2014). Skills, productivity and the evaluation of teacher performance.Economics of Education Review 40.183204. 68.

Husain, S., and Nazim, M. (2013). Concepts of knowledge management among library and information science professionals. International Journal of Information Dissemination and Tech nology, 3(4), 264-269.

Ilesanmi, T. C. (2013). Roles of the librarian in a research library in the digital era: Challenges and the way forward. New Review of Academic Librarianship. 19(1).

Ishola, B. C. (2014). Funding problems in Nigerian University libraries: Fee based library and information services to the rescue, focus on pricing policy. Library philosophy and practice (e-journal) paper 1176. Accessed online at

http://digitalscommons.unl.ed u/libphilprac/1176.
Jabar, M. A., Sidi, F., and Selamat, M. H. (2010). Tacit knowledge codification. Journal of Computer Science 6(10) 1170-1176.

Jegajothi, C., and Sudha, S. (2015). A study on organisational climate and employee performance management, 5(4).

Kebede, G. (2010). Knowledge management: An information science perspective. International Journal of Information Management. 30(15), 416-424.

Kim, Y. M., and Abbas, J. (2010). Adoption of library 2.0 functionalities by academic libraries and users: A knowledge management perspective. The Journal of Academic Librarianship. 6(3), 211-218.

Kubuga, K. (2014). Assessing the impact of organizational support on training and development: a case study of the University for Development Studies.A thesis submitted to the Department of Managerial Science, Kwame Nkrumah University of Science and Technology in partial fulfillment of the requirements for the degree of Masters in business administration (HRM option).

Lacewing, M. (2015). The dualcomponent view of belief. Routledge: Taylor \& Francis Group.

Lazarus, G. N., Unegbu, V, E., and Opeke, R. O. (2019). Professional competence, institutional support and documentation of indigenous knowledge in libraries in Lagos State, Nigeria. 
Lazarus, G.N., Jinadu, I., Eddy-Ugorji, D.C. and Imam, Abayomi: Institutional support for professional competence of librarians to improve the codification and preservation of traditional knowledge in the libraries

Information impact: Journal of Information and Knowledge Management, 10(2)153-166.

Leheman, L. L. (2011). The Importance of Library Today and into Tomorrow.Accessed online $27^{\text {th }}$ December, 2020 at http://www.sensingarchitectur e.com.

Leonard, B. (2001). Documenting indigenous knowledge and languages: Research planning $\&$ protocol. A newsletter of the Alaska Rural Systemic Initiative, 3(2) 13-16.

Mabawonku, I. M. (2002). The systematic management of Indigenous knowledge: a review of oral information projects in a library school. InSnyman, R. (ed.) SCECSAL 2002: From Africa to the world- the globalization of indigenous knowledge systems. Proceedings of the 15th Standing Conference of Eastern, Central and Southern African Library and Information Associations, 1519 April, Caesars Gauteng Conference Centre, South Africa. Pretoria: LIASA, p.4960.

Machaland, D., and Horvat, A. (2008). Competency-based lifelong learning of librarians in Croatia: an integrative approach. Journal of Education for Library and Information Science, 38(4) 283-302.

Makinde, O. O., and Shorunke, O. A. (2013). Exploiting the values of indigenous knowledge in attaining sustainable development in Nigeria: The place of library. Accessed online at: http://digitalcommons.unl.ed $\mathrm{u} /$ cgi/viewcontent.cgi?article $=2185 \&$ context $=$ libphilprac on $17^{\text {th }}$ December, 2020.

Matthew, H. (2013). Knowledge Management and the limits of knowledge codification. Journal of Knowledge Management 10(3) 220-227.

Mehta, K., Alter., T. R., Semali, L.M., and Audrey, M. (2016). Academic connections: Bringing indigenous knowledge and perspectives into the classroom. JCES, 6(2), 1-12. file:///E:/indig enous and classroom.htm

Morrow, P. C. (2011). Managing organisational commitment: Insights from longitudinal research. Journal of Vocational Behaviour, 14, 1835.

Mposhi, A.,, Manyeruke, C and Hamauswa, S. (2013). The importance of patenting traditional medicines in Africa: The case of Zimbabwe. International Journal of Humanities and Social Science.3(2).

Mulder, M. (2017).A five-component future competence model.The Journal of Agricultural Education and Extension, 23(2), 99-102.

Muswazi, P. (2001). Indigenous knowledge management in Swaziland: perspectives. Information Development, 17(4), 250-255.

Nakashima, D., Prott, L. and Bridgewater, P. (2000) Tapping into the world's wisdom. UNESCO Sources.tokforib.weebly.com/i ndigenous-knowledge.html.

Nakata, M. and Langton, M. (2005). Australian Indigenous 
Lazarus, G.N., Jinadu, I., Eddy-Ugorji, D.C. and Imam, Abayomi: Institutional support for professional competence of librarians to improve the codification and preservation of traditional knowledge in the libraries

Knowledge and Libraries. Australian Academic and Research Libraries, 36(2): 1211.

Nassazi, A. (2013). Effects of training on employee performance. Training and development of library staff: A case of two University libraries in Ghana. Library Philosophy and Practice (e-journal) 1794.unlib.unl.edu/Lpp/ on $22^{\text {nd }}$ October, 2020.

Nelson, D. L., and Quick, J. C. (2011). Organizational behavior: foundation realities and challenges $\left(4^{\text {th }} \mathrm{ed}\right)$. Australia: Thomas South- Western.

Ngulube, P. (2002). Managing and preserving indigenous knowledge in the knowledge management era: challenges and opportunities for information professionals. Information Development 18(2) 95-100.

Ngulube, P., Dube, L., and Mhlongo, M, (2015). Towards a cartography of indigenous knowledge system in library and information science training and education in anglophone Eastern and Southern Africa.IndilingaAfrican Journal of Indigenous Knowledge System, 14(2), 145-165.

Nnadozie, C. O., Nnadozie, C. D., Ogugua, J. C., Egwim, F. O., and Ossai-Onah, V. O. (2015). Management of indigenous knowledge in developing countries. Lagos: Zah Communication.

Nnadozie, C.O. (2013). Determination of indigenous knowledge in rural communities in transition Nigeria libraries.
Journal of the Nigeria library Association, 46 (1) 46-66.

Nwibere, B. H. (2014). Interactive relationship between job involvement, job satisfaction, organizational citizenship behavior and organizational commitment in Nigeria Universities. International Journal of Management and Sustainability. 3(6), 321-340.

Oguchi, D., Lamidi, A. D. and Gabassa, P. (2017). Capacity building for 1;ibrary and information professionals? Core skills and competence. International Jour nal of Applied Technologies in Library and Information Management.3(2).

Okoye, M. O. (2013). Assessment of Competencies of Professional Librarians in Nigeria. Library Philosophy and Practice (ejournal). 979. Accessed online at http :// digital commons.unl . edu/libphilprac/979 on 10th November, 2018.

Ondari-Okemwa, E. (2014). Ethical issues and indigenous knowledge production and use in organizational support and person-job fit. iBusiness, 2(4), 389-394.

Owiny, S. A., Mehta, K., and Maretzki, A. N. (2014). The use of social media technologies to create, preserve, and disseminate indigenous knowledge and skills to communities in East Africa. International Journal of Communication, 8(1), 234247.

Raseroka, K. (2015). Information transformation Africa: Indigenous knowledge securing space in the knowledge society. The International Information and 
Lazarus, G.N., Jinadu, I., Eddy-Ugorji, D.C. and Imam, Abayomi: Institutional support for professional competence of librarians to improve the codification and preservation of traditional knowledge in the libraries

Library Review, 40(4), 243250.

Ruggles, R. L. (2011). Knowledge management tools. Boston: Butterworth-Heinemann.

Sarkisov, P. D. (2018). Encyclopedia of Life Support Systems (EOLSS) Quality of human resources: education, vol. ii professional education.

Soh, M. C., and Omar, S. K. (2012). Indigenous knowledge for sustainable livelihood: Story from East coast, Malaysia. Journal of ASIAN Behavioral Studies, 2(7), 23-36.

Sturges, P. (2015). Career development in African librarianship.Library Trends. 64(1), 42-52.

Tella, R. D. (2007). Towards promotion and dissemination of Indigenous Knowledge: A case of NIRD, International Information and Library Review, 39.3-4: 185-93.

Thapan, M. (2006). Life at School: An Ethnographic Study. Oxford University Press, New Delhi.

Turner, N. J. (2014). Ancient pathways, ancestral knowledge: ethnobotary and ecological wisdom of indigenous people of North western, North America. Accessed online at https:// www.researchgate.net> publication on $12^{\text {th }}$ Oct, 2020.

Ugwu, C. I., and Ezema, I. J. (2010). Competencies for successful knowledge management applications in Nigerian academic

libraries.International Journal of Library and Information Science. 2(9), 184-189.

Ukwuoma, U. C. (2016). Educational development of Africa: Changing perspectives on the role of indigenous knowledge.
Botswana International Uni versity of Science and Technology. Accessed online at Doi:10.17810/2015.28 on $5^{\text {th }}$ November, 2018.

Uphoff, N., and Buck, L. (2006). Strengthening rural local institutional capacities for sustainable livelihoods and equitable development. Paper prepared for the Social Development Department of the World Bank, Washington, DC, Cornell, Cornell International Institute for Food, Agriculture and Development.

Ute, S., Uhlaner, L. M. and Stride, C.B. (2015). Institutions and social entrepreneurship: the role of institutional voids, institution al support and institutional configurations. Journal of Institutional Business Studies, 46(3)308-331.

Uzohue, C.E., and Yaya, J. A. (2016). Knowledge management competencies for library and information professional's century Nigerian libraries. American Journal of Business and Society, 1(3), 90-97.

Wendland, W. (2008) Libraries, intellectual property and traditional cultural expressions: Balancing access and control. Accessed online at: http://wo.ala.org/tce/wp on 27th November, 2020.

Wiseoneking, (2015). Thegiant pythons of Ihiala.Nairaland forum. Accessed online on $22^{\text {nd }}$ December, 2020 at http://www.nairaland.com/256 6661/giant-pythons-ihiala/2

World Bank. (2004). Local pathways to global development: Marking five years of the World Bank Indigenous Knowledge deve- 
Lazarus, G.N., Jinadu, I., Eddy-Ugorji, D.C. and Imam, Abayomi: Institutional support for professional competence of librarians to improve the codification and preservation of traditional knowledge in the libraries

lopment programs. Accessed online at http:// www.world bank.org/294C626A-6795459D-96A9-F1BFAF009DF0 /Final on 10th November, 2020.

Yunnus, F. (2017). Preservation of indigenous knowledge (IK) by public libraries in Westcliff, Chatsworth, Durban. Mini thesis submitted in partial fulfillment of the requirements for the degree of Masters in Library and Information Studies, University of the Western Cape. 